\title{
Ergonomic design of a cooling vest in deep and ultra-deep mining environments
}

\author{
Valérie Tuyêt Mai Ngô, Sylvie Nadeau* and Stéphane Hallé \\ École de technologie supérieure, Montréal, QC, Canada
}

\begin{abstract}
.
BACKGROUND: Ever deeper mining is exposing workers to increasing heat and humidity, which can threaten their health and safety.

OBJECTIVE: The objective of this research is to create a matrix of criteria that will eventually be used to design a personal cooling vest that will meet the needs and wants of miners.

METHODS: A literature review was done to identify the constraints and requirements of miners in ultra-deep mining conditions; a field study was conducted in which information was acquired by measurement (temperature, humidity), observation (work rate) and semi-directed interviews of a convenience sample, 20 volunteer participants (age, weight, height, shirt size, personal protective equipment currently worn and opinion about a cooling vest). The data was then structured, compiled and interpreted to create a matrix.

RESULTS: Participants were found to be in the $>50 \%$ percentile of the population regarding weight and height. All reacted positively to the idea of a cooling vest to help in their work. A matrix containing nine users and seven design-related criteria was created.

CONCLUSIONS: The matrix must still be tested as to its validity. Its usage could then be extended to other fields of work in which heat is a health and safety concern for workers.
\end{abstract}

Keywords: Ultra-deep mining, cooling equipment, ergonomic criteria

\section{Introduction}

The depletion of mineral resources, particularly of precious metals such as gold, in the earth's higher strata has led mining companies to follow current mineral deposits further into the earth [1] at a distance that qualifies mining as deep and ultra-deep (2 km and more) [2,3]. At these depths, miners are confronted to environmental conditions, which at the present time are a risk to their health and safety. The increase in depth means a rise in ambient temperature and this subjects the miners to heat stress, which is known to have a negative impact on physical work performance and to make people more prone to work-related accidents [4].

Part II of Canada's Labour Code entitled Occupational Health and Safety concerns "the elimination of hazards, then the reduction of hazards and finally, the provision of personal protective equipment, clothing, devices or materials, all with the goal of ensuring the health and safety of employees." [5] This implies that personal protective equipment (PPE) should always be used as a last resort in case

\footnotetext{
${ }^{*}$ Corresponding author: Sylvie Nadeau, Mechanical Engineering Department, École de technologie supérieure, Montréal, QC, Canada. Tel.: +1 514396 8672; E-mail: sylvie.nadeau@etsmtl.ca.
}

1359-9364/17/\$35.00 (c) 2017 - IOS Press and the authors. All rights reserved

This article is published online with Open Access and distributed under the terms of the Creative Commons Attribution NonCommercial License (CC BY-NC 4.0). 
of an occupational hazard that cannot be eliminated or controlled by other means. However, it is often necessary to ensure that the work can continue despite less than optimal working conditions.

The objective of our research was to create a matrix of ergonomic criteria for the design of a cooling vest for deep and ultra-deep mining workers. The method used to achieve this involved three activities: two literature reviews, one on the miners' constraints and requirements in deep and ultra-deep mining, and a second on PPE development and measures, semi-directed interviews and finally a field observation of miners.

\subsection{Background}

In deep and ultra-deep mining, heat and humidity may reach levels in excess of $35^{\circ} \mathrm{C}$ and $100 \%$ relative humidity [6]. These extreme thermal constraints will continue to rise as extraction continues at greater depths [4], which presents a real challenge as well as a threat to the health and safety of miners [7].

While air conditioning can and has been used to control temperature and humidity, it becomes a costly solution at great depths not only in terms of energy consumption, but also as to investment and maintenance costs $[7,8]$. In the literature reviewed, annual costs for ventilation and cooling systems start from $20 \%$ of the annual energy usage [9], 23\% of the operating costs [10], and 25\% of the mine's electricity costs [11]. It is thus a significant expense for any mine operation. Ventilation on demand has been looked at as a possible solution, since not every sector of a mine has either machinery or workers in it at all times [12]. However, this can only postpone the need for mechanical refrigeration.

In the near future, full automation of mining vehicles in Canada might not yet be deployed extensively and humans should and will continue to be at the forefront of operations [1]. Moreover, some mining equipment such as shuttle-cars are not always equipped with air conditioned cabins.

It is thought that a personal cooling vest might be a solution that could protect the workers as well as reduce the costs of the cooling of the mine. Several types of cooling vests exist on the market [1316], such as, air cooling garments, liquid cooling garments, cooling garments based on gas expansion, phase changing garments and thermoelectric cooling. In their work, Al Sayed et al. [17] list the many issues that may arise when using an ordinary cooling vest in deep underground mines, such as reduced cooling efficiency, risk of condensation on the interior of the vest, bulkiness of the apparel and low autonomy [17]. They conclude that no cooling technology is perfectly compatible with deep mining environments. A matrix of ergonomic criteria is thus a welcomed aid that could help in the design of such an equipment.

\subsection{Research problem}

Developing a PPE to help cool down the body of miners in extreme environmental conditions might be a less costly solution than the ones currently in use. While ventilation will always remain an essential part of a mine, a vest would bring the cooling directly to the miners who most need it.

Two key problems must be addressed: the working environment and conditions that it will be used in, as well as the workers wants and needs towards a new protective garment. The answers to these two problems will help create a matrix of ergonomic criteria, which will be used to develop an appropriate cooling vest.

\section{Methodology}

A sequential approach was used to answer the key problems. The first step consisted in a literature review on the constraints and requirements miners faced with deep and ultra-deep mining. This included 
an analysis of the PPE currently worn by the miners and the energy expenditure associated with the work in an underground environment [18].

Following the approval of the experimental protocol by the Ethics Committee of the École de technologie supérieure, the field study was conducted over four days in Abitibi-Témiscamingue. The economy of this region relies heavily on natural resources extraction industries and there are several deep and ultra-deep gold mines.

The field study allowed us to observe the working environment, as well as interview miners and retired miners. All the participants were informed of the aims of the research project and their right to voluntarily participate and withdraw at any time. The participants also gave their written informed consent. Semi-directed interviews and observations of the miners as well as temperature and humidity readings were then conducted.

The literature review conducted on constraints and requirements of miners in deep and ultra-deep mines was published by $\mathrm{Ngô}$ et al. [6]. It revealed the lack of data on deep and ultra-deep mining conditions and it was determined that a field study was necessary to collect missing key information. Little is known about the conditions workers face at those depths and, to the best of our knowledge, no case studies were found on the worker's metabolic rate under thermal stress in ultra-deep mines.

In total, 20 voluntary subjects, all male, were questioned during semi-directed interviews. The prevalence of men in the industry guided this choice, since only $4 \%$ of underground miners in Canada are women [19]. It was essential to determine how well miners would accept a new protective equipment. Basic data was collected, including each miner's weight, age and stature as well as their most commonly worn t-shirt size. This was then compared to data in the Human Scale [20] to determine if the miners had their own anthropometric category. To our knowledge, there is no existing anthropometric database specifically for Canadian miners. The miners were also asked if they had any concerns about the use of a cooling vest. The data was compiled and regrouped into themes, which became the criteria for the matrix, which was then defined.

PPE development literature was also examined to validate the criteria used in the matrix, as well as add those which had not been raised by the field study or the initial literature review, such as equipment maintenance.

\section{Results}

\subsection{Miners' receptivity towards a new PPE}

In the semi-directed interviews, participants were asked three questions: whether they thought a cooling vest would be a good PPE to be implemented, the reason why they thought so and if they would be willing to try out a future prototype.

All participants agreed that the environment was hot and humid and that a cooling vest would be beneficial to their work. Two miners spoke openly of their awareness of the consequences of heat exposure. They thought a cooling vest would help alleviate the risk of a heat stroke, as well as improve the worker's well-being during work. All 20 miners were in favor of trying out a prototype if it was made available to them. Three miners expressed some concerns regarding the weight and fit of the equipment.

\subsection{Population}

As mentioned, most Canadian mining workers are male. In the first half of the $20^{\text {th }}$ century, Polish 
Table 1

Summary of different measures of the participants

\begin{tabular}{lccccc}
\hline & Age (years) & Weight $(\mathrm{kg})$ & Height $(\mathrm{m})$ & Body mass index & T-shirt size \\
\hline Min & 23 & 65.8 & 1.70 & 20.2 & M \\
Max & 55 & 117.9 & 1.88 & 37.3 & $2 \mathrm{XL}$ \\
Average \pm standard deviation* & $37.2 \pm 10.7$ & $91.1 \pm 15.3$ & $1.78 \pm 0.05$ & $28.7 \pm 4.2$ & $75 \% \mathrm{~L}$ to XL \\
\hline
\end{tabular}

${ }^{*} \mathrm{~N}=20$

\section{Weight Distribution}

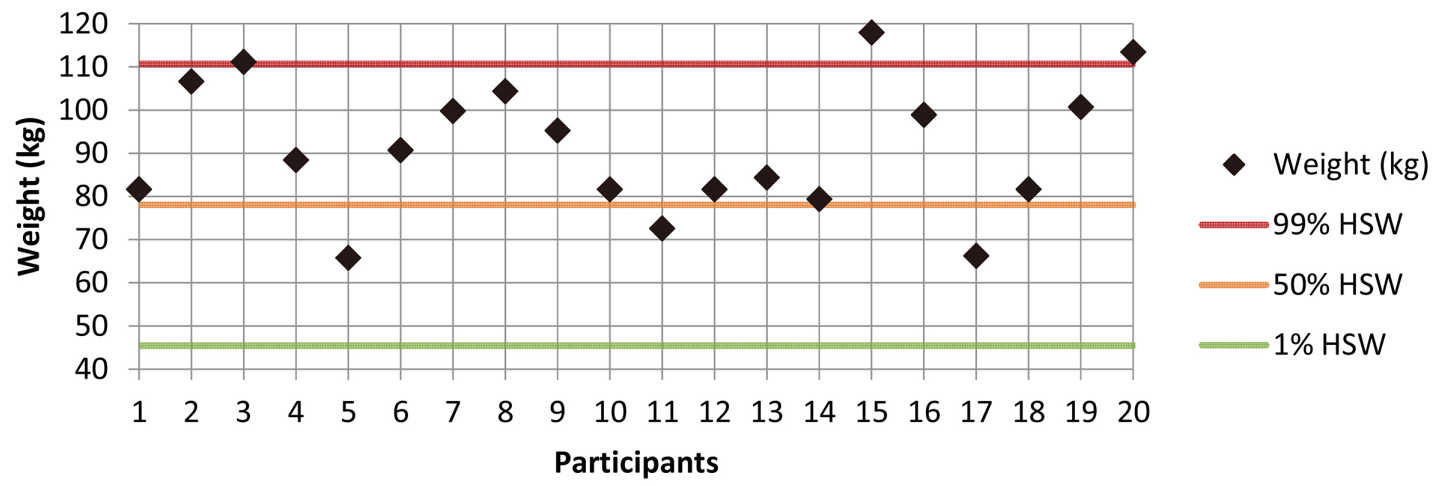

Fig. 1. Weight distribution of the participants. Weight of all the participants compared to "The measure of man and woman" [20] where the green line represent the $1^{\text {st }}$ percentile of the population, the yellow line the $50^{\text {th }}$ percentile and the red line the $99^{\text {th }}$ percentile.

immigrants came to settle in the region of northern Quebec [21]. They integrated the local communities to form the population that exists to this day. The data concerning the participants' weight, height and shirt size was collected during the field study. Due to time constraints, it was not possible to precisely measure each participant. Since the exactness of the data was unnecessary at this stage, their verbal descriptions were sufficient.

Table 1 summarizes the results, while Figs 1 and 2 compare weight and height with the Human Scale (1, 50 and 99 percentiles which are yellow, orange and red respectively) for each participant.

\subsection{Occupation}

The word miner refers to all classes and laborers who work in a mine. However, the tasks are different depending on the miners, for example the work of a manual drill operator will involve the whole body, compared to shuttle-car operators who are sitting while driving which requires less use of the upper or lower body. During the field study, a variety of miners were interviewed to ensure a larger scope of answers. Their class distribution is detailed below.

- 13 drill operators;

- 3 motormen;

- 2 construction workers;

- 1 shuttle-car operator;

- 1 supervisor. 


\section{Height Distribution}

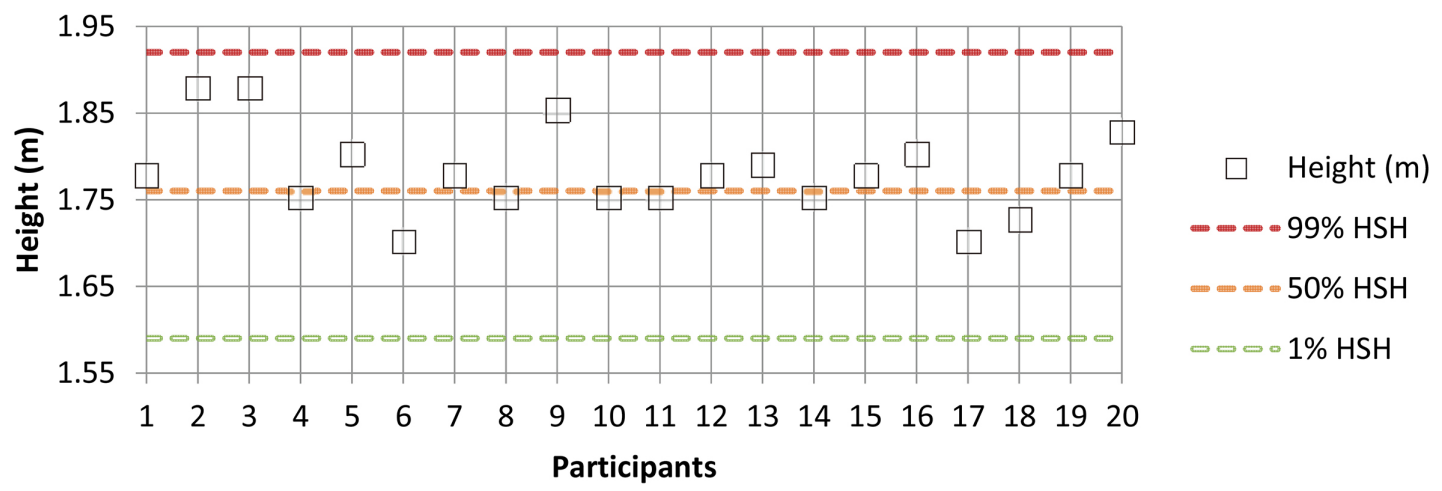

Fig. 2. Height distribution of the participants. Height of all the participants compared to "The measure of man and woman" [20] where the green line represent the $1^{\text {st }}$ percentile of the population, the yellow line the $50^{\text {th }}$ percentile and the red line the $99^{\text {th }}$ percentile.

Table 2

Heat and humidity at various depths in a mine

\begin{tabular}{clcc}
\hline Depth $(\mathrm{m})$ & Location & Dry temperature $\left({ }^{\circ} \mathrm{C}\right)$ & $\% \mathrm{RH}$ \\
\hline \multirow{2}{*}{1300} & Mechanical workshop & 21.8 & 64 \\
& On a mine roadway & 27.0 & $>99$ \\
& On a mine roadway with active shuttle-car operating & 28.8 & $>99$ \\
\multirow{2}{*}{1600} & On a mine roadway & 28.2 & 83 \\
& In a shelter with air conditioning (AC) on & 26.6 & 57 \\
& At the end of a mine roadway (while the AC system is off) & 35.1 & 98 \\
& Just outside the shelter (while the AC system is off) & 30.0 & $>99$ \\
& In a mine roadway (while the AC is off) & 35.0 & 76 \\
\multirow{2}{*}{ Average \pm 00} & Close to the small AC system & 28.8 & 69 \\
& On a mine roadway (while the AC system is off) & 30.0 & $>99$ \\
& & $29.1 \pm 3.1$ & $84 \pm 15$ \\
\hline
\end{tabular}

\subsection{Shift and break times}

The participants mostly worked on a 10-hour set shift; two of these worked 11 and 12 hours, respectively. Fourteen workers mentioned never taking a break except for lunch, or not at all. Observations showed that the workers do take "micro-breaks" when having a drink for example, or resting against a wall. They also stop working at times when they speak with their colleagues or supervisor. Having many short breaks is more beneficial, because of the steepness of recovery at the beginning of a work break [22]. Although the work objective is determined at the beginning of the day, 18 of the workers mentioned they self-pace while ensuring they complete the work in the allotted time. Seven mentioned taking a break because of the heat or based on their perception of their physical capacity.

\subsection{General work environment}

Temperature and humidity levels were recorded on four levels of the mine using a portable wind, humidity and temperature meter (Kestrel 3000 Wind Meter, uncertainty $1.4^{\circ} \mathrm{C}$ and $3 \% \mathrm{RH}$ ). The findings are shown in Table 2, where we can observe that high amounts of heat and humidity can be found at all levels, regardless of the depth. 
Table 3

List of PPE of a Mine in Quebec, Canada

\begin{tabular}{lll}
\hline Equipment & Mandatory/optional & Details \\
\hline Safety harness & Optional & When working at heights \\
Safety belt & Mandatory & Mandatory at all times \\
Hard hat and accessories & Mandatory & Earplugs mostly, no earmuffs \\
Safety shoes (or boots) & Mandatory & Boots generally \\
Respiratory protective & $\mathrm{SO}_{2}$ mask is mandatory & \\
equipment & $\mathrm{N} 95$ particulate filtering optional & \\
Safety glasses & Mandatory & Sometimes welding mask worn over the safety goggles \\
Gloves & Mandatory & $\begin{array}{l}\text { Some miners had gloves that reduced vibration (not pro- } \\
\text { vided by the employer) } \\
\text { They can also add on the overall which protects against } \\
\text { grease and other similar products }\end{array}$ \\
\hline
\end{tabular}

All shelters in the mine were equipped with an air conditioning unit, which would ordinarily help the miners during their cooldown period (such as a lunch break). However, to meet and possibly exceed their quota on time, some miners do not return to the cooling shelter at all during their work hours.

\subsection{Personal protective equipment}

Any additional PPE will have an impact on the existing PPE worn by miners or may even interfere or be incompatible with it. Thus, the type of PPE currently worn by miners needed to be determined. Table 3 establishes the mandatory and optional equipment used in the mine. The data was obtained both by questioning miners during semi-directed interviews and by obtaining the list of equipment from the health and safety team of the mine. When designing a cooling vest, this equipment will need to be considered.

\subsection{Impact on the worker's body}

The miners were asked if their garment snagged on wires or other mine hazards in the mine or if they used any vibrating tool or if they had been struck during their work. They were asked to use an outline of a human to annotate where various events happened on their body, and this diagram helped us generate a heat map. The heat map was used to visualise, using colors, the areas where the workers considered themselves more at risk of getting hit or snagged on wires or other mine hazards (Fig. 3). Heat maps can also be used to show a thermal environment similar to what an infrared camera would show [23].

Figure 3 illustrates the areas which are considered more or less at risk of impact, vibration or snagging on wires or other mine hazards. The numbers on the figure indicate the frequency at which it was mentioned by a participant and the colour value is as follows: 1-3 Yellow, 4-6 Orange, 7-10 Red. The choice of colors was intended to make it easy to distinguish them on a scale of importance and facilitate visual interpretation when printing in grayscale, by respecting that a darker color means a higher value $[24,25]$. The area that was mentioned the most was the arms, because the sleeves tend to get caught on the protective wiring on the mining shaft walls. The head was mentioned, because of the type of light used in the participating mine, which requires a wire that connects to a battery at the waist. Some mining hats are now equipped with an integrated battery in the hardhat which eliminates that risk. The feet were mentioned because of the absorption of vibrations during the use of manual drills when the worker supports the equipment with his body. The objective of this map is to prevent damage to the future PPE during the time it is worn and minimizing any potential risks to the user. 


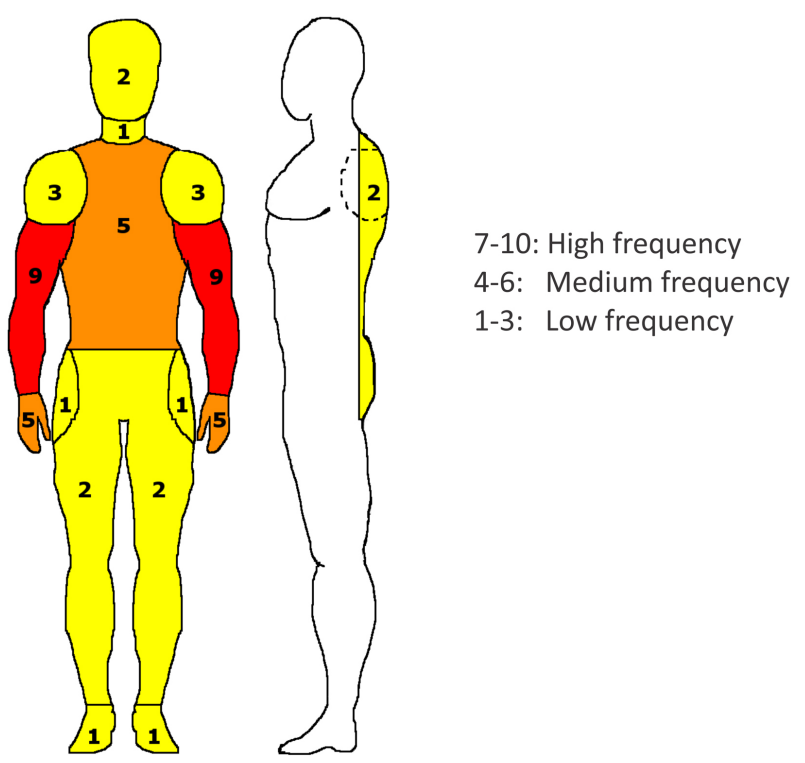

Fig. 3. Areas at risk of getting hit or snagged. Areas of the body, perceived by the interviewed miners, as being at risk of getting hit or snagged by elements of the miner's environment.

\section{Value of criteria}

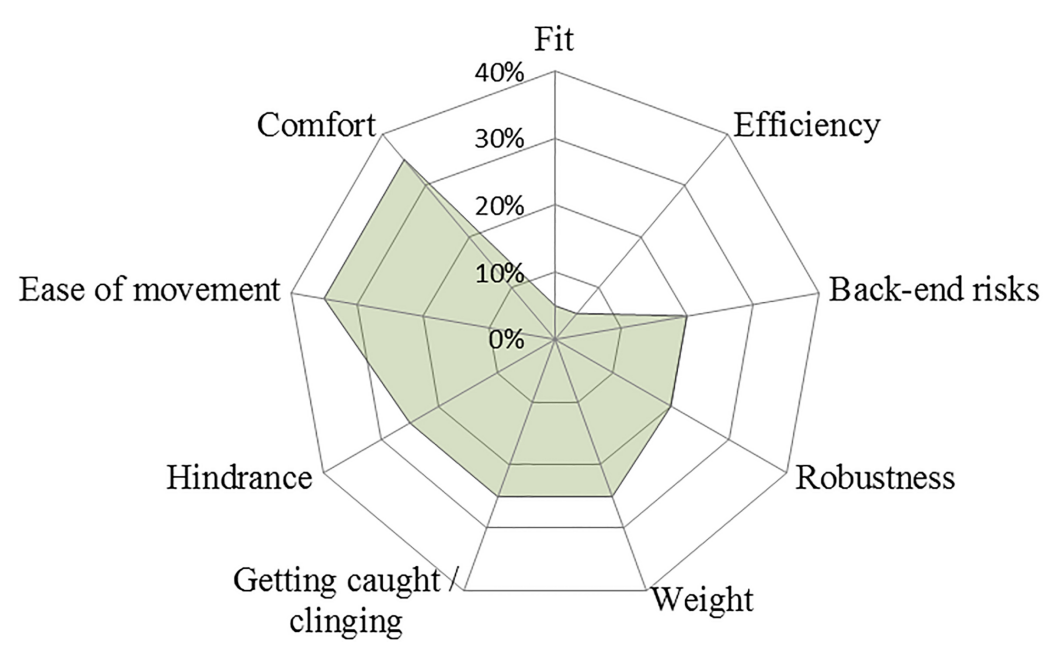

Fig. 4. Concerns raised by the participants. Concerns the miners had about potential new personal protective equipment.

\subsection{Concerns about a new PPE}

An open question was asked to the participants as to their concerns regarding a cooling vest. The data was compiled and is shown in Fig. 4. We can observe that comfort and ease of movement are primary concerns, while efficiency and fitting did not cross their minds or seem to matter as much. With directed questions, it is possible that the results would have differed. 


\subsection{Additional criteria established by Normal PPE development literature}

\subsubsection{Design aesthetics and usability}

An article by Sonderegger and Sauer [26] identifies two criteria from the perspective of design aesthetics, the outward look and attractiveness, which refers to the individual's reaction to a product. Multiple studies have proven that aesthetics and attractiveness have had an influence on the perceived usability of a product [27,28]. Moreover, sometimes a performant equipment can be discarded in favor of an aesthetically pleasing equipment for the sake of the perceived image.

\subsubsection{Maintenance}

Koo et al. [29] mention two factors in their design of protective gardening gloves: durability and ease of care, which we merged into one category, maintenance of the equipment. Durability can be both mechanical resistance and the ability to keep its properties over time. Ease of care includes the time, costs, space and resources necessary to maintain an equipment in its proper state [30].

\subsubsection{Conformity to laws, regulations and standards}

Different countries will have different laws, regulations and standards. Any new PPE must conform to those and should be designed using the latest and most stringent standards, according to the best practices.

\subsection{Final matrix setup}

The final matrix setup is show in Table 4. The criteria are separated into two categories: one is centered on the user, while the other is centered on the general design of the equipment. The definition of each criteria is based on existing literature. The columns weight of criteria and selected method of evaluation should be completed in further studies using expert elicitation.

\section{Discussion}

The main objective of this research was to establish a matrix of ergonomic criteria that a cooling vest would have to meet to satisfy the needs and expectations of miners. Currently existing cooling vests are not appropriate for use in deep mining conditions [17]. While the safety, efficiency and autonomy of the apparel will be more centric to the designers, comfort and ease of movement will be a top priority to convince miners to try out the cooling vest. This finding is similar to the results of Chan et al. [31], which state that the worker's preference for a cooling vest is related to the wearer's comfort and its impact on job performance although the perceived feeling of safety and the fit of the cooling vest were also mentioned.

\subsection{Limited number of participants and time constraints}

In a mine, the environment and situation is constantly changing. Miners are always on the move. Each day, even multiple times in a single day, changes in work schedule and assignment can occur. For these reasons, we could not effectively plan where and when we would meet the miners and if they would have time to answer our questions. This is the main reason why this study was limited to 20 participants, a convenience sample, even though a larger sampling would have been preferable.

The time constraints on our side and that of the miners and the mining company, meant the numbers related to weight, height and t-shirt size were obtained from the miner and were not directly measured. 
Table 4

Final design matrix of a personal cooling vest suited to deep mining conditions

\begin{tabular}{|c|c|c|c|}
\hline Category & Information source & Criteria & Definition \\
\hline User & $\begin{array}{l}\text { Weight, height, } \\
\text { shirt size, concerns }\end{array}$ & Fit & $\begin{array}{l}\text { "Quality, state or manner towards the length and close- } \\
\text { ness of clothing worn by the human body" [33] }\end{array}$ \\
\hline User & $\begin{array}{l}\text { Impact on the } \\
\text { worker's body, } \\
\text { Concerns }\end{array}$ & Robustness & $\begin{array}{l}\text { The resistance to all types of factors including impact, } \\
\text { heat, humidity, vibration, dust, etc. }\end{array}$ \\
\hline User & Concerns & Weight & The weight of the cooling vest \\
\hline User & Heat map, concerns & Snagging & $\begin{array}{l}\text { Fabric or vest should not get caught on rock surface or } \\
\text { other protuberance; (of a garment) fitting closely to the } \\
\text { body and showing its shape }\end{array}$ \\
\hline User & $\begin{array}{l}\text { PPE, Heat map, } \\
\text { concerns }\end{array}$ & Hindrance & $\begin{array}{l}\text { "A thing that provides resistance, delay, or obstruction } \\
\text { to something or someone" (Oxford Dictionary) }\end{array}$ \\
\hline User & PPE, concerns & $\begin{array}{l}\text { Ease of movement/ } \\
\text { mobility }\end{array}$ & $\begin{array}{l}\text { "The ability to move or be moved freely and easily" } \\
\text { (Oxford Dictionary) }\end{array}$ \\
\hline User & Concerns & Comfort & $\begin{array}{l}\text { Thermal and tactile comfort - "Thermal: clammy-dry, } \\
\text { airtight-breathable, damp-dry, sticky-nonadhesive, hot- } \\
\text { cool; Tactile: Prickly - non-prickly, Itchy - non-itchy, } \\
\text { scratchy - non-scratchy" [15] }\end{array}$ \\
\hline User & Literature review & Design aesthetics & $\begin{array}{l}\text { Objective features of a stimulus or subjective reaction } \\
\text { to the specific product feature [26] }\end{array}$ \\
\hline User & Literature review & Usability & $\begin{array}{l}\text { The ease at which the user can understand how to wear } \\
\text { and use the protective equipment }\end{array}$ \\
\hline Design & $\begin{array}{l}\text { General work } \\
\text { environment, concerns }\end{array}$ & Efficiency & $\begin{array}{l}\text { "The effectiveness with which a task or operation is } \\
\text { done; usually measured in energy spent, cost, or time } \\
\text { required. For muscular work, efficiency is a measure of } \\
\text { how much of the energy is translated into useful me- } \\
\text { chanical work compared to the total amount: mechan- } \\
\text { ical plus that dissipated as heat. Most muscle work is } \\
\text { less than } 25 \text { percent efficient" [34] }\end{array}$ \\
\hline Design & Concerns & Back-end risks & Remaining risks after design is complete \\
\hline Design & Literature review & Working environment & $\begin{array}{l}\text { The setting or conditions in which activity is carried on } \\
\text { (Oxford Dictionary) }\end{array}$ \\
\hline Design & Literature review & Energy expenditure & $\begin{array}{l}\text { "The power used during activity or rest. It is usually } \\
\text { expressed in Watts, in kilocalories per minute or hour, } \\
\text { or in milliliters of oxygen per kilogram of body weight } \\
\text { per minute ( } \mathrm{ml} \mathrm{O}_{2} / \mathrm{kg} \text { bw/min)" [34] }\end{array}$ \\
\hline Design & Literature review & Maintenance & $\begin{array}{l}\text { "Maintenance should include inspection, care, cleaning, } \\
\text { repair, and proper storage" [30] }\end{array}$ \\
\hline Design & $\begin{array}{l}\text { Price range of a cooling } \\
\text { vest }\end{array}$ & Cost & $\begin{array}{l}\text { "(of an object or action) requires the payment of (a spec- } \\
\text { ified sum of money) before it can be acquired or done" } \\
\text { (Oxford Dictionary) }\end{array}$ \\
\hline Design & Literature review & $\begin{array}{l}\text { Conformity to existing } \\
\text { laws, regulations and } \\
\text { standards }\end{array}$ & \\
\hline
\end{tabular}

While it might have added a level of error, we considered that it would be negligible in terms of the answer to the question: what size should a vest be for a miner? Obviously, in the case of a fitted vest, more measures should be considered such as the ones for the coverall, harness and other items fitted on the body depending on whether the vest is inside or outside the coverall.

\subsection{Population}

During our search on miner's anthropometry, we were unable to find any specific database pertinent to our mining population in Quebec, and even in Canada. In his thesis, Boudreau-Trudel [32], states that 
our mining population in Abitibi-Témiscamingue comprises both French Canadians, English Canadians and two waves of Polish, Ukrainian and Italian immigrants. This is also confirmed by Lambert-Racine and St-Pierre [21].

Due to the previously mentioned absence of a specific database on Canadian miners, the data that was used for comparisons came from The Measure of Man and Woman [20], also known as the Human Scale. It is based on civilian anthropometric data from the 90s (Pheasant 1996, Roebuck 1995) and The Military Handbook: Anthropometry of U.S. Military Personnel (DoD, 1991), which means the data is already two decades old.

According to Figs 1 and 2, miners are within the normal range defined by $98 \%$ of the U.S. population from 2002. This is shown clearly by the boundary lines for the 1,50 and 99 percentiles which are yellow, orange and red respectively.

\subsection{Variability of working environment conditions}

We needed to meet the miners in four different levels of the mine, since their working environment (heat, humidity, type of work) and availability differed depending on the mine level and also, we wanted to have the largest possible representation of the population. This also influenced the rate at which they were seen to take "micro-breaks" and we can make the general hypothesis that self-pacing is also affected in the same way.

We believe the heat and humidity measures that were taken during the four days of field study represent what a miner endures in general. However, we can hypothesize that the temperature might rise even more during the summer season. Also, even though we could have consulted the records on the mines' temperatures as recorded by static thermometers throughout the year, these readings are not always relevant since they might not be from an area of the mine where the workers will be exposed to those conditions.

The main reason miners were found to be receptive to the idea of a cooling vest was because their working environment was already hot and humid as seen in Table 2. Miners in a working environment where cooling systems are in use might not be as receptive to the idea since their work conditions differ.

\subsection{Price of equipment}

In Québec, Canada, legislation states that the employer must supply the necessary protective equipment to their workers at no cost. Thus, workers who already are experiencing heat in their current working conditions, but are still able to deliver and meet their objectives, might not be willing to invest in PPE if the employer does not provide it.

\subsection{Impacts on the worker's body}

Any new cooling vest should be resistant to impacts and vibrations in the critical areas of the heat map shown in Fig. 3. Critical components should not cover the sections in red, and should be evaluated for the sections in orange and yellow, unless proper precautions are taken.

\section{Conclusion and future research}

Deep and ultra-deep mining is an unavoidable development for the future. Miners will be confronted with heat and humidity beyond acceptable levels. A PPE, although usually used as a last resort, could help ensure that the work continues while protecting the workers until a more effective means of heat stress reduction can be achieved. 
To the best of our knowledge, there exists no known matrix of ergonomic criteria to help achieve a proper design of a PPE that would help the miners in their struggle.

The literature review and field study enabled us to develop a matrix of ergonomic criteria. This matrix, once validated, can be used for the design of a new PPE that will help miners faced with heat stress in deep and ultra-deep mining conditions.

In future work, it might be possible to apply this matrix to other work environments where heat and humidity are problematic and it is hoped that it will eventually be widely implemented to improve all types of cooling vests.

\section{Acknowledgments}

We would like to thank Fonds de recherche du Québec - Nature et technologies (FQRNT), École de technologie supérieure and the Association Québécoise pour l'hygiène, la santé et la sécurité du travail for providing financial support for this research.

\section{Conflict of interest}

None to report.

\section{References}

[1] Nadeau S, Badri A, Wells R, Neumann P, Kenny G, Morrison D, editors. Sustainable canadian mining: Occupational health and safety challenges. 57th Human Factors and Ergonomics Society Annual Meeting - 2013, HFES 2013, September 30, 2013 - October 4, 2013; 2013; San Diego, CA, United States: Human Factors an Ergonomics Society Inc.

[2] Webber RCW, Franz RM, Marx WM, Schutte PC. A review of local and international heat stress indices, standards and limits with reference to ultra-deep mining. Journal of The South African Institute of Mining and Metallurgy. 2003; 103(5): 313-23.

[3] Ultra Deep Mining Network. The business of mining deep: Below 2,5 kms: UDMN; 2016.

[4] Wagner H. The management of heat flow in deep mines. Mining Report. 2013; 149(2): 88-100.

[5] Canada Labour Code Sect. Part II: Occupational Health and Safety, 2017.

[6] Ngô VTM, Nadeau S, Mackowiak J, Hallé S. Ergonomic challenges in designing personal cooling equipment for ultradeep mining. In: Advances in Ergonomics in Design: Proceedings of the AHFE 2016 International Conference on Ergonomics in Design, Rebelo F, Soares M, editors, 27-31 July 2016, Walt Disney World ${ }^{\circledR}$ Florida, USA. Cham: Springer International Publishing; 2016. pp. 757-67.

[7] Hardcastle S, editor. Controlling personnel heat exposure in Canada's deep and highly mechanized mines. 11th US/North American Mine Ventilation Symposium - 11th US/North American Mine Ventilation Symposium 2006, June 5, 2006 June 7, 2006; 2006; University Park, PA, United states: Taylor and Francis/Balkema.

[8] Trapani K, Romero A, Millar D. Deep mine cooling, a case for Northern Ontario: Part II. International Journal of Mining Science and Technology. 2016; 26(6): 1033-42.

[9] Uys DC, Kleingeld M, Cilliers C, editors. Converting an ice storage facility to a chilled water system for energy efficiency on a deep level gold mine. 2015 International Conference on the Industrial and Commercial Use of Energy (ICUE), 1819 Aug 2015; Piscataway, NJ, USA: IEEE.

[10] Goosen P, Pelzer R, du Plessis HJ, editors. A method for accurate electricity budget cost calculations for a deep mine. 2015 International Conference on the Industrial and Commercial Use of Energy (ICUE), 18-19 Aug 2015; 2015; Piscataway, NJ, USA: IEEE.

[11] van Jaarsveld S, du Plessis JN, Pelzer R, editors. A control system for the efficient operation of bulk air coolers on a mine. 2015 International Conference on the Industrial and Commercial Use of Energy (ICUE), 18-19 Aug 2015; Piscataway, NJ, USA: IEEE.

[12] Hardcastle S, Kocsis C, O'Connor D, editors. Justifying ventilation-on-demand in a Canadian mine and the need for process based simulations. 11th US/North American Mine Ventilation Symposium - 11th US/North American Mine Ventilation Symposium 2006, June 5, 2006 - June 7, 2006; 2006; University Park, PA, United states: Taylor and Fran- 
cis/Balkema.

[13] Bendkowska W, Bogdan A, Kopias K, Klonowska M, editors. Thermal manikin evaluation of microclimate cooling vests containing PCMs. 4th International Textile, Clothing and Design Conference - Magic World of Textiles, ITC and DC, October 5, 2008 - October 8, 2008; Dubrovnik, Croatia: Faculty of Textile Technology.

[14] Branson DH, Farr CA, Peksoz S, Nam J, Cao H. Development of a prototype personal cooling system for first responders: User feedback. Journal of ASTM International. 2005; 2(2): 274-84.

[15] Chan APC, Yang Y, Wong DP, Lam EWM, Li Y. Factors affecting horticultural and cleaning workers' preference on cooling vests. Building and Environment. 2013; 66: 181-9.

[16] Delkumburewatte GB, Dias T. Wearable cooling system to manage heat in protective clothing. Journal of the Textile Institute. 2012; 103(5): 483-9.

[17] Al Sayed C, Vinches L, Hallé S. Towards optimizing a personal cooling garment for hot and humid deep mining conditions. Open Journal of Optimization. 2016; 5(1): 35.

[18] Kenny GP, Vierula M, Mate J, Beaulieu F, Hardcastle SG, Reardon F. A field evaluation of the physiological demands of miners in Canada's deep mechanized mines. Journal of Occupational and Environmental Hygiene. 2012; 9(8): 491-501.

[19] Women in Mining Canada. Ramp-UP: A Study on the Status of Women in Canada's Mining and Exploration Sector. Canada: Mining Industry Human Resources Council, 2010.

[20] Henry Dreyfuss Associates, Tilley AR. The measure of man and woman: human factors in design. Rev. ed. ed. New York: Wiley; 2002, p. 98

[21] Lambert-Racine S, St-Pierre M. Les mines de l'Abitibi-Témiscamingue: un héritage culturel. Commission de la santé et la sécurité du travail. 2010; Le Belmine (29): 4-5.

[22] Kroemer KHE. Fitting the Human: Introduction to Ergonomics, Sixth Edition: CRC Press; 2008.

[23] Morgado M, Talaia M, Teixeira L. A new simplified model for evaluating thermal environment and thermal sensation: An approach to avoid occupational disorders, 2015.

[24] Borland D, Ii RMT. Rainbow Color Map (Still) Considered Harmful. IEEE Computer Graphics and Applications. 2007; 27(2): 14-7.

[25] Harrower M, Brewer CA. ColorBrewer.org: An online tool for selecting colour schemes for maps. The Cartographic Journal. 2003; 40(1): 27-37.

[26] Sonderegger A, Sauer J. The influence of design aesthetics in usability testing: Effects on user performance and perceived usability. Applied Ergonomics. 2010; 41(3): 403-10.

[27] Lamb JM, Kallal MJ. A conceptual framework for apparel design. Cloth Text Res J. 1992; 10(2): 42-7.

[28] Lombardi DA, Verma SK, Brennan MJ, Perry MJ. Factors influencing worker use of personal protective eyewear. Accident Analysis and Prevention. 2009; 41(4): 755-62.

[29] Koo HS, Teel KP, Han S. Explorations of design factors for developments of protective gardening gloves. Cloth Text Res J. 2016; 34(4): 257-71.

[30] Desjardins-David I. L'évaluation des équipements de protection individuelle utilisés en milieu de travail: Considérations et méthodologie proposée [MIng.]. Ann Arbor: Ecole de technologie supérieure (Canada); 2010.

[31] Chan APC, Yang Y, Yam MCH, Lam EWM, Hu JY. Factors affecting airport apron workers' preference on cooling vests. Performance Enhancement \& Health. 2016; 5(1): 17-23.

[32] Boudreau-Trudel B. Impact et facteurs dés de l'introduction d'équipements miniers innovants: Le cas d'une mine souterraine [DEng.]. Ann Arbor: École de technologie supérieure (Canada); 2014.

[33] ASTM. Standard Practice for Body Measurements and Sizing of Fire and Rescue Services Uniforms and Other Thermal Hazard Protective Clothing. West Conshohocken, PA: ASTM International; 2013. p. 10.

[34] Eastman Kodak Company. Kodak’s Ergonomic Design for People at Work: Wiley, 2004. 